are a nuisance to the patient who has to bear a certain amount of inconvenience, an frequent visits to a chiropodist or to his general practitioner.

They are a nuisance to the patients' general practitioner who feels he is being pestere for such a lowly condition (and doesn't know what to do about it) and is likely to be

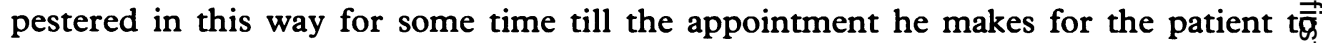
attend a general surgical or orthopaedic outpatients comes to fruition.

They are a nuisance to the general or orthopaedic surgeon who feels there are more momentous things to do and relegates the ingrowing toe nail to be done by the senio house officer at the end of his waiting list for patients to be called in for mino? operations.

In spite of all the above, and certainly not because of the above, ingrowing toe nail $\overrightarrow{8}$ are NOT accidents and/or emergencies.

Accident and emergency departments face a lot of problems. One of the maiê problems is having to deal with patients attending inappropriately on their own 0 having been referred to accident and emergency departments inappropriately by theit general practitioners.

The introduction or encouragement of treatment for ingrowing toe nails as añ accident and emergency responsibility is only the thin edge of a very big wedge. Ther 8 are a lot of other conditions (a nuisance to patients and general practitioners alike) which would come to be considered germane to the speciality of accident and emergenct medicine and surgery if we give patients or their general practitioners half the chance $e_{-}$

The specialities who now, and rightfully, have to deal with verrucas, warts, cornsw dermatoses, tennis/golfer's elbow, frozen shoulders, varicose veins, ear wax, perres rhinitis, menstrual irregularities and habitual overdosers (to name a few) would be ople too glad if accident and emergency departments volunteered their services to usurp the treatment of such cases.

IRFAN F. MIRZA

Accident Service,

Burnley General Hospital,

Burnley, Lancashire,

England

\title{
The seat-belt sign
}

\section{Sir}

The letter published in the last edition of Archives of Emergency Medicine (Volume 3 Number 4, December 1986) by Rainey \& Ritchie described an unusual clinical sigh following negative peritoneal lavage which prompted early diagnosis of a retroperitof neal duodenal ulcer.

This case clearly reinforces the growing pile of evidence in support of the 'Seat-befir sign' as an important indicator of the likelihood of intra-abdominal injury following seat-belt trauma to the abdomen.

The seat-belt syndrome was first described by Garrett \& Braunstein in 1962 but the 
term 'seat-belt sign' appeared in an article by Doersch \& Dozier in 1968. The sign is positive if there is patterned bruising on the chest or abdominal wall corresponding to the position of the diagonal or horizontal strap of the seat-belt. There is usually associated abdominal tenderness or guarding, but this may be minimal. Patients presenting to the accident and emergency department with a positive seat-belt sign, even without other clinical signs, should be expected to have intra abdominal trauma and be closely observed. Some authors advocate laparotomy purely on the strength of this sign alone (Shamblin, 1968; Rouse et al., 1984).

In the case described in the letter by Rainey $\&$ Ritchie, the clinical signs were minimal and peritoneal lavage was performed. This gave a negative result but subsequently the patient developed surgical emphysema around the stab wound and sub-diaphragmatic gas on X-ray. Laparotomy was performed and revealed retroperitoneal gas and bilestained fluid associated with a $2-\mathrm{cm}$ tear on the posterior surface of the junction of the second and third parts of the duodenum.

I would hypothesise that it is unlikely that gas from the duodenal tear had caused the surgical emphysema around the peritoneal lavage stab wound or the sub-diaphragmatic gas.

From the description given, the blunt trauma to the duodenum at the junction of the second and third parts would only give rise to retroperitoneal leakage and it is difficult to see how this could track into the anterior abdominal wall or under the hemi diaphragm.

It is well recognised that gas enters the abdominal peritoneal cavity during peritoneal lavage both through the air in the tubing and leakage on removal of the catheter, and I would, therefore, propose that the clinical sign described, namely surgical emphysema around the stab wound, was entirely iatrogenic.

I would accept the statement that diagnosis and treatment of the retroperitoneal duodenal rupture is often delayed due to the lack of clinical signs. I have previously described a case of isolated pancreatic damage following seat-belt injury (Freeman, 1985) and the diagnosis did not become apparent until the development of a pseudocyst. However, the presence of a positive seat-belt sign should alert the emergency physician to the likelihood of serious intra-abdominal trauma and laparotomy should be performed sooner rather than later.

\section{P. FREEMAN}

Senior Registrar in Accident and Emergency Services, East Birmingham Hospital, Birmingham, England

\section{REFERENCES}

Doersch K. B. \& Dozier W. E. (1968) The seat-belt syndrome. American fournal of Surgery 116, 831-3.

Freeman C. P. (1985) Isolated pancreatic damage following seat-belt injury. Injury 16, 478-80.

Garrett J. W. \& Braunstein P. W. (1962) The seat belt syndrome. fournal of Trauma 2, 220-38.

Rouse T., Collin J. \& Daar A. (1984) Isolated injury to the intestine from blunt abdominal injury. Injury 16, 131-3.

Shamblin J. R. (1968) Seat-belt injuries. Archives of Surgery 97, 474-7. 